\title{
Do Poverty Reduction Strategies and Agricultural Policies Engage in West and Central Africa?
}

\section{Abdou Salam Fall and Thiendou Niang}

\section{Introduction}

At its 2003 meeting, the steering committee of the Agricultural Policy Expertise Network (REPA) decided to focus the network's research on the articulation between poverty reduction strategies (PRS) and agricultural policies. The purposes of the study were: to critically review the PRS (orientations, objectives, priority actions and axes of interventions); to assess the participatory approach and the decision-making process; and to analyse the coherence (compatibility and complementarities) between the PRS and agricultural policies at national and regional levels. The study focuses on the agricultural sector given the size of the rural population, the prevalence of rural poverty, the contribution of agriculture to gross domestic product (GDP) and its provision of livelihoods to the vast majority of the population. The research methods included a literature review of available documents on the topic produced by national institutions and international organisations such as the New Partnership for Africa's Development (NEPAD), the West African Economic and Monetary Union (WAEMU), the Economic Community Of West African States (ECOWAS) and the Economic and Monetary Union of Central Africa (CEMAC). The countries covered in the study were those which have at least two years of experience with PRS and have delivered at least a progress report (Benin, Cameroon, Mali, Burkina Faso, Niger, and Senegal). This article draws on the expert studies and the regional synthesis and covers an evaluation of PRS (design, implementation and monitoring) and of agricultural policies at both national and regional levels (Baye and Douya 2004; Hamadou and Mohamadou 2004; Martin et al. 2004; Zerbo et al. 2004). It suggests some recommendations for improving future PRSs and policies.

\section{Poverty reduction strategies and agricultural policies}

Despite being introduced long after agriculture policies, Poverty Reduction Strategy Papers (PRSP) often focus on the agricultural sector for priority investment. Although it has long been the basis of the economy in West and Central Africa, the adoption of neoliberal policy prescriptions in the agricultural sector (removal of protection of agricultural systems, free trade, promotion of export crops) has resulted in scant attention being paid to poor populations by public policies. This implies that the PRSP refers to agricultural policies but adopts a different orientation. Also, sector-based agricultural programmes (rural infrastructure and support to agricultural services), which preceded the PRSP, are not merged with the latter but run parallel to them. Various policy documents have been produced for agriculture, livestock, the environment, etc. Each features priorities and strategic options regarding the sub-sector, but articulation with the other subsectors has received little attention. The weak links between the unit dealing with poverty and the various ministerial departments, in almost every country should also be noted. The new programmes created in various countries, following the PRSP and relating to poverty, refer to the PRSP without detailing the forms of coordination.

IDS Bulletin Vol 36 No 2 June 2005 @ Institute of Development Studies 
Consultation processes around the PRSP have been extensive, but the hectic pace of schedules in most countries did not encourage deep and forwardlooking discussion by all stakeholders. Debates and discussions often seemed unfinished. The participatory process was sometimes reduced to an ex post validation, and some civil society actors viewed the PRSP as nothing more than a new opportunity for consultancy work. In some countries, the participation of non-governmental organisations (NGOs) in the PRSP process led to their fragmentation and resulted in duplication. The NGO factions that were created were limited to the popularisation of PRSP provisions. In some cases, interest groups such as trade unions paved the way for revision of the PRSP to prioritise their own concerns (protecting or creating jobs).

Even where civil society participation had some effect on the priority given to rural development, too little consideration was given to this in most PRSP documents. In addition, the targeting of poor people and vulnerable groups has not, paradoxically, been properly addressed, either within the PRSP or by agricultural policies. In order to reach the poor, targeting should be part of the guiding principles for implementing the PRSP, and not just as a technical mechanism to follow up living conditions of vulnerable groups. To reach poor people, programmes should target poor and vulnerable individuals, groups and zones and should have an in-built reliable monitoring and evaluation mechanism, which is permanent and free of any attempts at vote catching. PRSPs have focused on the creation of wealth plans on how to involve the poor. Moreover, targeting should also concern vulnerable areas and territories, as well as individuals. The social basis of activities, and their articulations with local development processes, are thus essential for poverty reduction strategies and the PRSP ignores such issues.

PRSPs call for a national budget provision and an allocation of resources with a close involvement of state-owned services. However, during 25 years of structural adjustment policies characterised by restrictions on recruitment, voluntary redundancies, etc., civil services faced declining employment, superseded by parallel divisions, which are ad hoc investment agencies. As a result, at all stages of the PRSP process, but particularly during the design and implementation phases, technical inadequacies were a hindrance to work programmes. The disappearance of planning units raises the issue of technical capacity of ministries, while the lack of concerted government actions raises the issue of coordination between ministries. The procedural impediments brought by donors make it difficult to access their resources (Republic of Senegal 2004). Their hidden agendas create some ambiguities and uncertainties in defining policies. Additionally, the application and implementation of PRSPs requires restoring and renewing trust in government to avoid or minimise distortions, dysfunctions and biases of any kind.

Senegal provides an example of a risk linked to such a global approach without any targeting mechanism. With the application of the PRSP, taxation was reduced for seeds and fertilisers in 2003. But, given the lack of targeting mechanisms, these inputs were bought and stored by traders and big producers, who sell them freely on the market at the expense of the poorer producers. Also, inequalities leading to poverty have not been addressed by either the PRSP or agricultural policies. Land reform, the relationship between family owned farms and bigger farms, subsistence and export crops, gender inequalities, access to the market and international regulations are ignored, while they constitute the major obstacles to economic take-off.

\section{Poverty Reduction Strategy Papers (PRSPs)}

PRSPs are meant to be the centrepiece of states' development policies, but their national ownership remains inadequate. Although national PRSPs have not been conceived in private, unlike many economic policy papers, their relationship to Bretton Woods Institutions reduces their legitimacy and leads to suspicions that they are watered down extensions of structural adjustment policies. Unlike the consultative process followed during the design of national PRSP, sub-regional PRSPs are likely to be designed in private, or according to a technocratic approach, strongly influenced by - or under the supervision of - the World Bank. Many stakeholders interviewed as part of this study thought that changes brought by PRSP show that there have been some reforms in selected areas, bearing in mind the previous submissions of African governments to the Bretton Woods Institutions in the definition of public policies. However, the prospect of debt cancellation would make for multi-dimensional governance, indispensable for state rebuilding and the creation of better-informed agricultural policies. 
At this stage in the implementation of the PRSP, we cannot yet measure the impact of these programmes on poverty reduction, but if about half of (global as well as external) resources remain unused by governments, the ability to fulfil the proclaimed ambitions of the PRSPs will inevitably be questioned. The method of integrating additional Heavily Indebted Poor Country (HIPC) resources into national budgets is not efficient. The low capacity for absorption of public resources including HIPCs of West and Central African countries - calls into question the aggressive option for accelerated growth rates, which are the basis of the PRSP.

\section{Regional agriculture policies}

National and regional agricultural policies and poverty reduction policies converge towards a common point: intensification of agriculture, which basically calls for a new approach to production, a renewal of agricultural equipment, new land policies, price incentive policies, coordinated interaction between different actors and sub-sectors, improved facilities and massive new investment. Despite their commonalities, these regional policies have been characterised by varied efficiency.

Recent drops in income from the main West African cash crops (groundnuts, cotton and cocoa) catapulted food traders to the frontline, but this important shift from cash crops to food crops destined for local and regional markets is not recognised in agricultural policy agendas. The market for food producers seems to be the channel through which a decisive revolution in family farming will occur. Food traders in West and Central Africa have been very successful thanks to the dynamism of the domestic market, as seen through the accelerated development of weekly rural markets and the presence of big producers (of cash crops) or traders who have switched over to food crops. A comparative study of the various agricultural policies suggests a shared vision at both national and regional levels. The regional organisations share a view of agriculture being the locomotive of economic development, for regional blocs and Africa as a whole. Unfortunately, the share of crops in the added value of the sector is continually being eroded since the various programmes are poorly integrated. The agricultural mandates of institutions such as ECOWAS, WAEMU, CEMAC and to a lesser extent, NEPAD are overlapping, but there are poor articulations between regional and national policies (with such national peculiarities as the contrast between roots-producing and -consuming countries and those that mainly produce cereals). WAEMU, ECOWAS, CEMAC and PRSP have some common priorities and parallel approaches that are, however, poorly coordinated. The key priority that recurs in all policies is to achieve food security, defined as availability and access to enough food for all. This target is echoed in the launch of the ECOWAS common agricultural policy formulation process (in November 2004). It is a feature of CEMAC's common agricultural policy, and that of WAEMU. It is also one of the main characteristics of NEPAD's agricultural component. But the question remains as to what has been actually done at regional level in order to meet the needs of cross-border populations.

While goodwill exists to change the trend of deepening poverty in rural areas and marginalisation in the world market, rural poverty continues to expand and adds to the complex conditions of deprived urban populations. There is a need for an alternative paradigm. The tax of 10 per cent on cereal imports and 20 per cent on all other manufactured goods falls short of expectations in the light of the World Trade Organization's (WTO) initial promises. The WAEMU's common external tariff does not protect agriculture in the Union. Farmers' associations demand, for instance, that products like rice be moved from Grade 2 (10 per cent of customs duty) to Grade 3 (20 per cent of customs duty). One of the main irregularities noted flows from the fact that WAEMU countries themselves determine a rate for customs duties, which they pledge to stick to, whereas the common external tariff was determined before the agricultural policy of the Union. With all these constraints, subSaharan Africa will not meet the objective of reducing poverty by half.

\section{Recommendations}

The study concludes with a series of recommendations concerning participation, the targeting of interventions, the promotion of processing industries, gender mainstreaming, sectorbased policies, resource mobilisation and a new development vision.

To promote a truly participatory PRSP and agricultural policies, four conditions are necessary. First, government should create a framework for a 
critical debate on the participation of civil society, the private sector and local communities in the definition, implementation and evaluation of public policies, especially regarding poverty. Second, optimal conditions for non-governmental stakeholders to influence the PRSP (priorities implementation, evaluation, resourcing) should be established. Third, government should contract specialised institutions to conduct and facilitate the participation of non-governmental stakeholders in agricultural policies aimed at the co-production of such policies and the creation of social consultations. Finally, government should contract research and development institutions to uphold lessons learnt by PRSP stakeholders, and to lay down the foundations for organised planning in the definition of development strategies.

Targeting the poor or moderately poor and vulnerable agro-ecological areas should be the main guiding principles in implementing the PRSP and in the choice of priorities. It should be the main criterion for evaluating PRSPs' impact. PRSPs should aim to do away with inequalities in the long term. Land reforms are necessary, in particular by tapping into experiences of land management and reallocation. Participatory approaches and joint planning would help to reduce inequalities and secure equitable access to means of production and resources. PRSPs should operate within a larger framework of development planning, to stimulate rural development through addressing structural factors and re-launching production in the primary sector (protecting the agricultural food chain, enhancing food security). Opening up isolated rural areas and increasing rural infrastructure, as well as setting up equipment to store agricultural products and valorising sub-products (cattle breeding, fishing, horticulture) would all promote rural development.

PRSPs should call for credible and stable institutions, a public service for development, and the creation of strong social institutions capable of guaranteeing safe redistribution of growth products. Such reliable institutions in various sectors microfinance, housing, inputs supply and sale of products - would improve economic efficiency and promote social cohesion.

To go beyond the usual discourse and the unfulfilled expression of good intentions, rural development stakeholders should set up suitable novel methods and tools that allow full expression of such a paradigm. Consequently, governments should also create conditions leading to the PRSP monitoring with the involvement of genderspecialised institutions.

To encourage and promote the creation of coherent sector-based policies and programmes, policy formulation based on a bottom-up approach, mastering statistical information and drawing on social science studies are essential for appropriate targeting of poor and vulnerable people. It is useful to extend the temporal horizon of the PRSP, while making provision for reviews at regular intervals. Governments should play a fully proactive role, particularly in sectors where the private sector is weak and especially in response to external forces (natural disasters, perverse effects of international trade, etc.).

The process of mobilising resources remains complex. It is necessary to make them flexible, to bring them into line with one another, and to harmonise them to boost their implementation rate and responsiveness to social demand. Governments should speed up budgetary and financial reforms to simplify public expenses procedures. The competence of governments and stakeholders involved in the preparation, implementation and evaluation of programmes aimed at the poor should be increased. For greater efficiency of public expenditure, it is necessary to reduce transaction costs in favour of field activities.

\section{Conclusion}

State legitimacy should be reinforced through the introduction of democracy, not just as a basic principle, but also as a modus operandi for access to power, business management, transparency and good governance, with civil society being the state's strategic partner. Under a democratic regime, the stronger civil society is, the stronger the government. Consequently, reinforcing civil society amounts to reinforcing state legitimacy. The bad effects of debt servicing on national and regional economies point to the need to cancel debt in order to release energies and make the most of opportunities. Continuing to export raw cash crops leaves countries in a pricetaker's position, and constrains the exponential economic growth needed in developing countries. These countries should aim to export semi-processed or processed agricultural and manufactured products and, through adding value, acquire a "price-maker" status. It would also be wise to harvest researchers' technological inventions to start exporting 
technological products with a high added value in the international market. The importance of the agricultural sector (which involves more than half the population) in stimulating growth and redistribution of income calls for greater consideration of its specificity. The sector should be seen only as part of a global approach including all sector activities and stakeholders. For essentially agricultural countries, a significant drop in food imports through sustained and regular production, plus more effective negotiation capacities in the

\section{References}

Baye, F.M. and Douya, E., 2004, 'Stratégies de réduction de la pauvreté et politiques agricoles au Cameroun', Draft Report, under the coordination of P. Moumie, permanent secretary of PAM, Dakar: Réseau d'Expertise des Politiques Agricoles

Hamadou, S. and Mohamadou, A., 2004, Articulation entre stratégies de réduction de la pauvreté et politiques agricoles: Cas du Niger, Dakar: Réseau d'Expertise des Politiques Agricoles world market, are the main channels for improving farmers' living conditions and consequently the eradication or reduction of poverty. In a changing Africa, it is imperative to consolidate the internal dynamics of the society to meet the objectives of food sovereignty and to become the artisan of one's own future. Such a vision will be fulfilled only in societies genuinely striving for social change, democracy, the protection of the environment and human development.

Martin, G., Sossou, A.F. and Adjovi, E.G., 2004, Stratégies de réduction de la pauvreté et les politiques agricoles: Cas du Bénin, Dakar: Réseau d'Expertise des Politiques Agricoles

Republic of Senegal, 2004, Progress Report on the PRSP Implementation, 2003, Dakar: Ministry of Economy and Finance

Zerbo, K., Kabore, S.T. and Drabo, K., 2004, Stratégies de réduction de la pauvreté et les politiques agricoles: Burkina Faso, Dakar: Réseau d'Expertise des Politiques Agricoles 